\title{
Sarcopenia and consumptive syndrome in HIV-infected patients receiving antiretroviral therapy in a public hospital in Northeast Brazil
}

\section{Sarcopenia y síndrome de emaciación en pacientes infectados por el HIV que reciben terapia antiretroviral en un hospital público en el noreste Brasil}

\begin{abstract}
We evaluated the prevalence of sarcopenia and wasting syndrome, as well as the associated factors in HIV-infected patients receiving antiretroviral therapy. We utilized a cross-sectional study evaluating HIV-infected individuals at a university hospital in the Northeast area of Brazil. In 99 patients, sarcopenia was assessed by analysis of muscle mass, muscle strength and physical performance. Wasting syndrome was assessed by unintentional weight loss criteria. Demographic, socioeconomic, anthropometric, as well as clinical and lifestyle variables were also evaluated. The prevalence of sarcopenia in this sample was $18.2 \%$ and $33.3 \%$ presented severe sarcopenia. Wasting syndrome was identified in $13.1 \%$ and $4 \%$ presented both conditions. Sarcopenia had higher prevalence in older patients (80.0 vs $4.9 \%, p=0.004$ ), among those with diabetes mellitus (50.0 vs $16.1 \%, p=0.037$ ), as well as among malnourished individuals $(p=0.003)$. Wasting syndrome was more prevalent in individuals with a lower level of education (26.3\%vs5.4\%, $p=0.005)$, in the lower income tertile $(p=0.041)$, and a lower $C D 4+T$ cell count $(429 \pm 450$ vs $654 \pm 321 \mathrm{cells} / \mathrm{mm}^{3}, p=0.045$ ). Sarcopenia and wasting syndrome are still clinical problems present in those using antiretroviral therapy associated with specific conditions in HIV patients.

Keywords: HIV; Malnutrition; Sarcopenia; Wasting syndrome.
\end{abstract}

\section{RESUMEN}

Se evaluó la prevalencia de la sarcopenia, síndrome de emanciación y factores asociados en pacientes infectados por HIV que recibieron terapia antirretroviral. En la evaluación de las personas infectadas por el HIV se aplicó un diseño de tipo transversal y fue realizado en un hospital universitario en la zona noreste del Brasil. La sarcopenia se evaluó mediante la medición de la masa muscular, la fuerza muscular y el rendimiento físico. El síndrome de emanciación se evaluó mediante criterios de pérdida de peso involuntarios. También se evaluaron las características demográficas, socioeconómicas, antropométricas, así como las variables clínicas y de estilo de vida. La prevalencia de sarcopenia en esta muestra de pacientes fue del 18,2\%,

\begin{abstract}
Luciana Caroline Paulino do Nascimento ${ }^{1,4^{*}}$, Eryka Maria dos Santos², Lídia Laís Gomes Silva ${ }^{3}$, Claudia Porto Sabino Pinho 4 .
\end{abstract}

\begin{abstract}
*Corresponding Author: Luciana Caroline Paulino do Nascimento, Rua Sargento Wilson Viana, n³09, Tejipió, Recife/PE - Brasil. Email: lucianacpnascimento@hotmail.com
\end{abstract}

1. Department of Nutrition, Federal University of Paraíba, João Pessoa, PB, Brazil; 2. Department of Surgery, Federal University of Pernambuco, Recife, PE, Brazil; 3. Department of Nutrition, Federal University of Pernambuco, Recife, PE, Brazil; 4. Clinical Hospital, Federal University of Pernambuco, Recife, PE, Brazil.

Este trabajo fue recibido el 17 de junio de 2019. Aceptado con modificaciones: 24 de septiembre de 2019. Aceptado para ser publicado: 22 de diciembre de 2019.

y de esta población un tercio presentó sarcopenia grave. El síndrome de emanciación se identificó en el 13,1\% de los pacientes y en el $4 \%$ de los sujetos que presentaron ambas condiciones. La sarcopenia tenía mayor prevalencia en pacientes de mayor edad (80,0 vs 4,9\%, $p=0,004)$, en las personas con diabetes mellitus (50,0 vs 16, $1 \%, p=$ $0,037)$, así como en sujetos desnutridos $(p=0,003)$. El síndrome de emanciación fue más prevalente en sujetos con un nivel más bajo de educación $(26,3 \%$ vs 5,4\%, $p=0,005)$, menor tercil de ingresos $(p=0,041)$, y menor recuento de células TCD4+ (429 450 vs $654 \pm 321$ células/ $\left.\mathrm{mm}^{3}, p=0,045\right)$. Sarcopenia y síndrome de emanciación son todavía problemas clínicos presentes en aquellos que utilizan la terapia antirretroviral asociada con condiciones 
específicas en pacientes con HIV.

Palabras clave: Desnutrición; HIV; Sarcopenia; Síndrome de emanciación.

\section{INTRODUCTION}

Medical complications associated with Acquired Immune Deficiency Syndrome (AIDS) have been considerably reduced since the utilization of antiretroviral therapy (ART) in Human Immunodeficiency Virus (HIV) and AIDS positive patients. The use of ART has contributed to reduction in mortality indexes and has also improved quality of life in patients affected by this devastating disease ${ }^{1}$. However, patients affected by AIDS commonly present several chronic complications. These complications, including cardiovascular, renal, hepatic and bone diseases are commonly associated with aging ${ }^{2}$. Additionally, evidence indicates that weight loss and muscle mass deterioration both continue to contribute to significant complications. These complications can be observed even in populations who have access to specific and potent therapy ${ }^{3}$.

Nutritional changes are commonly observed among individuals infected with HIV ${ }^{4,5}$. This effect is related to decreased appetite, insufficient energy intake and 'increased energy expenditure at rest' observed in HIV-positive patients. In addition, these metabolic changes can contribute to the loss of muscle mass, which is often associated with loss of strength and / or functionality, causing sarcopenia ${ }^{6}$. It is noteworthy to mention that sarcopenia can lead to a greater risk of physical disability, poor quality of life, as well as greater morbidity and mortality indexes ${ }^{7,8,9}$. Recent research protocols have reported that HIV patients who regularly use ART can represent a group at high-risk for the development of sarcopenia ${ }^{10,11}$.

Furthermore, HIV-associated wasting syndrome can be a debilitating and fatal complication ${ }^{12}$. This HIVassociated syndrome is characterized by total weight loss; i.e. loss of both lean and fat mass. Although there is a decrease in wasting syndrome after starting ART, this syndrome remains a concern for the patients affected by the virus ${ }^{13,14}$. For instance, Wheeler et al showed an increased risk of death in HIV-infected patients with progressive weight loss ${ }^{15}$, as well as long-term functional impairment even after recovery of nutritional status ${ }^{16}$.

Even though both sarcopenia and wasting syndrome can compromise quality of life and increase morbidity and mortality indexes of HIV patients ${ }^{17}$, there are few studies describing the magnitude of the physiological changes caused by these conditions in HIV patients. Additionally, there is a lack of data regarding the physiological actions of sarcopenia and wasting syndrome in HIV patients who use ART. Therefore, the present study evaluates the prevalence of sarcopenia and wasting syndrome, as well as associated factors in HIV patients who also received ART in a outpatient clinic.

\section{METHODS}

A cross-sectional observational study was carried out from March to June 2017 at the Parasitic Infectious Diseases outpatient clinic of a university hospital in Recife, Brazil. All male and female patients were 18 years of age and older. In order to participate in the study protocol, patients could not present any physical deficiencies or conditions that would compromise their ability to perform the tests and evaluation required by this present study. Data were collected during medical visits.

The sample size was calculated considering a prevalence of sarcopenia of $35 \%$, obtained in a previous pilot study, and a standard error of $5 \%$. Thus, the calculated sample size obtained was of at least 87 individuals, which was increased by $15 \%$, totaling 101 patients.

Sarcopenia was determined as proposed by Cruz-Jentoft et al $^{9}$. The diagnosis was made if there was a significant reduction of their muscle mass and a reduction of strength and/or reduction of physical performance. The measurement of muscle mass was assessed by arm muscle circumference (AMC). Muscle mass was considered of low mass when AMC values were lower than the 10 th percentile for age and sex ${ }^{18}$.

Muscle strength was measured via hand grip strength (HGS) in triplicate using a JAMAR ${ }^{\circledR}$ digital dynamometer. Muscle strength was determined to be low by definition of the sex and BMI cut-off points described by Cruz-Jentoft et al ${ }^{9}$. Physical performance was evaluated through the gait speed test (GST). This test was performed in duplicate according to the model proposed by the International Academy on Nutrition and Aging (IANA) ${ }^{19}$. Participants were instructed to walk by maintaining their usual pace through a 4-meter course. For each participant, the course performed in the shortest period of time was adopted as their baseline reference. Gait speed was considered slow at $<0.8$ meters / second. Sarcopenia was classified as pre-sarcopenia (non-sarcopenia, but displaying reduced muscle mass), sarcopenia (reduction of muscle mass associated with reduced strength and / or reduced physical performance) and severe sarcopenia (when all 3 conditions were found).

Wasting syndrome was assessed according to unintentional weight loss reported by the patient and was diagnosed when the patient had one of the following criteria: unintentional weight loss of $10 \%$ in 12 months or unintentional weight loss of $7.5 \%$ in 6 months, or unintentional weight loss $>5 \%$ in 3 months $^{20}$.

In addition, a number of clinical variables were evaluated. For instance, the period of time since HIV diagnosis (in months), the length of time taking ART treatment (in months), viral load (categorized as detectable and undetectable), and number of CD4 + T cells $\left(\leq 350\right.$ and $>350$ cells $\left./ \mathrm{mm}^{3}\right)$. Additionally, the 
occurrence of diabetes mellitus (DM), chronic kidney disease (CKD), and the presence of anemia, fatigue and anorexia were also evaluated. The Dutch Fatigue Scale (DUFS) (a self-report scale) was used to evaluate fatigue. Briefly, the DUFS scale measures fatigue as an "oppressive and sustained feeling of exhaustion and diminished ability to perform physical and mental work at the usual level"21. This scale is composed of 8 items with Likert responses of up to 5 points ( 1 to 5 points). The presence of fatigue was defined when the total score was greater than or equal to $14.5^{22}$. In addition, the evaluation of anorexia was performed using the Simplified Nutritional Questionnaire of Appetite (SNAQ). The range of values in this questionnaire can vary from 4 to 20 . Values $\leq 14$ were considered to indicate the presence of anorexia ${ }^{23}$.

Lifestyle analysis included assessment of three aspects. First, alcohol intake was categorized as yes or no for alcohol consumption in the last 30 days. Second, smoking was determined as smokers, non-smokers, and former smokers. Lastly, the level of physical activity was evaluated by the International Physical Activity Questionnaire (IPAQ) 2001. This questionnaire takes into account four levels of physical activity: leisure, domestic activities, occupational activities and activities related to displacement. These levels of activity can be classified as sedentary, irregularly active, active and very active ${ }^{24}$. For analytical purposes, the level of physical activity was dichotomized into sufficiently active (active and very active) and insufficiently active (sedentary and irregularly active).

Patients' nutritional state was evaluated according to individual Body Mass Index (BMI), obtained from the quotient between Weight $(\mathrm{kg})$ and height $(\mathrm{m})^{2}$. Adults were evaluated according to the World Health Organization ${ }^{25}$ and elderly participants were evaluated according to the cut points proposed by Lipschitz ${ }^{26}$.

Collected data were entered into Microsoft Office Excel 2010 and imported into SPSS statistical software version 13.0 (SPSS Inc., Chicago, IL, USA). All continuous variables were tested for normality of distribution using the Kolmogorov Smirnov test. When presenting normal distribution patterns, data were described with means and standard deviations and, the respective parametric test was applied (Student's " $t$ "). If the data presented a non-normal distribution (time since HIV diagnosis and time using ART treatment), data were described as median and interquartile range (IQ). In this case, the non-parametric " $U$ " test of Mann Whitney was used to evaluate the data. Qualitative variables were described in proportions and compared using Pearson's Chi-square test or Fisher's exact test. The results were considered significant when $\mathrm{p}<0.05$.

The current research protocol was approved by the Research Ethics Committee involving human, according to Resolution 466/2012 of the National Health Council.
The registration number of the research protocol is CAAE: 62327716.0.0000.5208, and the collection of data was initiated after the participants signed the Free and Clarified Consent Term (FCCT).

\section{RESULTS}

A total of 101 eligible patients were included in the initial sample. However, the final sample was composed of 99 patients, after excluding for inconsistent information. The mean age of participants was $41 \pm$ 11 years, with a predominance of males $(67.7 \%)$. The median time since HIV diagnosis was 60 months (IQ: 24-132) and the time since beginning ART treatment was 48 months (IQ: 20-108). Regarding the clinical variables analyzed, viral load was undetectable in $57 \%$ of the patients and the CD $4+\mathrm{T}$ cell count was $>350$ cells $/ \mathrm{mm}^{3}$ in $76.3 \%$. Anemia $(17.2 \%)$, hypertension $(12 \%), \mathrm{DM}(6.1 \%)$ and CKD $(5.1 \%)$ were the most prevalent clinical parameters. About $60 \%$ of the patients presented fatigue and $19.2 \%$ presented anorexia. Regarding lifestyle variables, it was observed that $46.9 \%$ of patients consumed alcoholic beverages, $19.2 \%$ were smokers and $68.7 \%$ were sufficiently active (Table 1 ).

Undernutrition and overweight were observed in $8.2 \%$ and $47.5 \%$ patients, respectively. Based on the diagnostic criteria for sarcopenia, $18.2 \%$ presented with sarcopenia, and of this population, $33.3 \%$ presented with severe sarcopenia. Among non-sarcopenic patients, $16 \%$ had pre-sarcopenia. When analyzing sarcopenia criteria separately, we observed that there is a presence of three components (i.e. physical performance, mass and muscle strength) involved in the diagnosis of sarcopenia. The presence of these three components was relatively similar among participants (about $30 \%$ ). Unintentional weight loss was reported by $23.2 \%$ of the patients, but wasting syndrome was only identified in $13.1 \%$ of these patients (Table 2 ). Sarcopenia and wasting syndrome were both observed in $4 \%$ of the patients.

When evaluating the association of sarcopenia with demographic, socioeconomic, clinical and lifestyle variables, we observed that this condition was more prevalent in the elderly population $(80.0$ vs $14.9 \%$, $\mathrm{p}=0.004)$, in patients with DM (50.0 vs $16.1 \%$, $p=$ $0.037)$, and malnourished patients $(p=0.003)$. We did not observe an association between sarcopenia and other clinical variables, with lifestyle or wasting syndrome (Table 3 ).

Regarding the factors associated with wasting syndrome, we observed a higher prevalence in individuals with a less education $(26.3 \%$ vs $5.4 \%$, $p=$ $0.005)$, lower income $(p=0.041)$ and lower CD4+ T cells $\left(654 \pm 321\right.$ vs $429 \pm 450$ cells $\left./ \mathrm{mm}^{3}, \mathrm{p}=0.045\right)$. There was no statistically significant association of wasting syndrome with other demographic and clinical variables (Table 4). 
Table 1. Demographic, socioeconomic, clinical and lifestyle characterization of HIV-infected patients using antiretroviral therapy (ART), 2017 ( $n=99)$.

\section{Variables}

Socio-demographic variables

Sex

Male

Female

Age Category

Adult

Elderly

Education (years of study)

$\leq 9$ years

$>9$ years

Family income per capita (in real)

1st tertile ( $>333.33)$

2nd tertile (333.33-1000.00)

3rd tertile $(>1000.00)$

Clinical Variables Viral Load

Indetectable

Detectable

CD4+T (cells $\left./ \mathrm{mm}^{3}\right)$

$\leq 350$

$>350$

Systemic Arterial Hypertension (SAH)

Diabetes Mellitus (DM)

Chronic Kidney Disease(CKD)

Anemia

Fatigue

Anorexia

Lifestyle

Consumption of Alcoholic Beverages

Smoking

Smoker

Non-smoking

Former smoker

Level of Physical Activity

Sufficient active

Insufficiently active
28.1

54.2

17.7

57.7

42.3

23.8

76.3

12.1

6.1

5.1

17.2

60.0

19.2

19

46

46.9

19

19.2

60

60.6

20

20.2

68

68.7

31

$\%$

3

4

.


Table 2. Nutritional variables, sarcopenia and wasting syndrome in HIV-infected patients using antiretroviral therapy (ART), $2017(n=99)$.

\section{Variable}

Nutritional status (BMI)

Undernutrition

Eutrophy

Overweight

Sarcopenia

Yes

No

Sarcopenia classification

Sarcopenia

Severe Sarcopenia

Not sarcopenia classification

No sarcopenia

68

Pre-sarcopenia

Diagnostic Components of Sarcopenia

Low muscle massa ${ }^{a}$

Low muscle strength ${ }^{b}$

Unintentional weight loss

Wasting syndrome ${ }^{\mathrm{d}}$

81

13

13 n

$\%$

81.8

16.0

33.3

29.9

23.2

13.1

BMI: Body Mass Index. ${ }^{\text {a }}$ According to Muscular Circumference of the Arm;

${ }^{\mathrm{b}}$ According to palmar grip strength; ${ }^{\mathrm{c}}$ According to Speed test; ${ }^{\mathrm{d}}$ According to unintentional weight loss of $10 \%$ in 12 months or unintentional weight loss of $7.5 \%$ in 6 months or unintentional weight loss $>5 \%$ in 3 months. 
Table 3. Factors associated with sarcopenia in HIV-infected patients using antiretroviral therapy $($ ART), 2017 ( $n=99)$.

\begin{tabular}{|c|c|c|c|c|c|}
\hline \multirow[t]{2}{*}{ Variable } & \multicolumn{2}{|c|}{ No Sarcopenic } & \multicolumn{2}{|c|}{ Sarcopenic } & \multirow[t]{2}{*}{$p^{*}$} \\
\hline & $\mathbf{N}$ & $\%$ & $\mathbf{n}$ & $\%$ & \\
\hline Sex & & & & & 0.095 \\
\hline Male & 52 & 77.6 & 15 & 22.4 & \\
\hline Female & 29 & 90.6 & 3 & 9.4 & \\
\hline Age category & & & & & 0.004 \\
\hline Adult & 80 & 85.1 & 14 & 14.9 & \\
\hline Elderly & 1 & 20.0 & 4 & 80.0 & \\
\hline Education & & & & & 0.603 \\
\hline$\leq 9$ years & 32 & 84.2 & 6 & 15.8 & \\
\hline$>9$ years & 47 & 83.9 & 9 & 16.1 & \\
\hline Family income per capita & & & & & 0.530 \\
\hline 1st tertile (>333.33) & 21 & 77.8 & 6 & 22.2 & \\
\hline 2nd tertile (333.33-1000.00) & 45 & 86.5 & 7 & 13.5 & \\
\hline 3rd tertile (>1000.00) & 15 & 88.2 & 2 & 11.8 & \\
\hline Viral load & & & & & 0.336 \\
\hline Undetectable & 38 & 84.4 & 7 & 15.6 & \\
\hline Detectable & 25 & 75.8 & 8 & 24.2 & \\
\hline CD4+T (cells/mm³) & & & & & 0.333 \\
\hline$\leq 350$ & 14 & 73.7 & 5 & 26.3 & \\
\hline$>350$ & 51 & 83.6 & 10 & 16.4 & \\
\hline $\mathrm{SAH}$ & & & & & 0.624 \\
\hline Yes & 10 & 83.3 & 2 & 16.7 & \\
\hline No & 71 & 81.6 & 6 & 18.4 & \\
\hline DM & & & & & 0.037 \\
\hline Yes & 3 & 50.0 & 3 & 50.0 & \\
\hline No & 78 & 83.9 & 15 & 16.1 & \\
\hline CKD & & & & & 0.642 \\
\hline Yes & 4 & 80.0 & 1 & 20.0 & \\
\hline No & 77 & 81.9 & 17 & 18.1 & \\
\hline Anemia & & & & & 0.230 \\
\hline Yes & 11 & 73.3 & 4 & 26.7 & \\
\hline No & 62 & 84.9 & 11 & 15.1 & \\
\hline Fatigue & & & & & 0.591 \\
\hline Yes & 49 & 81.7 & 11 & 18.3 & \\
\hline No & 32 & 82.1 & 7 & 17.9 & \\
\hline
\end{tabular}


...Table 3 continued.

\begin{tabular}{|c|c|c|c|c|c|}
\hline \multirow[t]{2}{*}{ Variable } & \multicolumn{2}{|c|}{ No Sarcopenic } & \multicolumn{2}{|c|}{ Sarcopenic } & \multirow[t]{2}{*}{$\mathrm{p}^{*}$} \\
\hline & $\mathbf{N}$ & $\%$ & $\mathbf{n}$ & $\%$ & \\
\hline \multicolumn{5}{|l|}{ Anorexia } & 0.306 \\
\hline Yes & 14 & 73.7 & 5 & 26.3 & \\
\hline No & 67 & 83.8 & 13 & 16.3 & \\
\hline \multicolumn{5}{|c|}{ Consumption of Alcoholic Beverages } & 0.215 \\
\hline Yes & 40 & 87.0 & 6 & 13.0 & \\
\hline No & 41 & 78.8 & 11 & 21.2 & \\
\hline \multicolumn{5}{|l|}{ Smoking } & 0.099 \\
\hline Smoker & 13 & 68.4 & 6 & 31.6 & \\
\hline Non- smoking & 53 & 88.3 & 7 & 11.7 & \\
\hline Former smoker & 15 & 75.0 & 5 & 25.0 & \\
\hline \multicolumn{5}{|l|}{ Level of Physical Activity } & 0.838 \\
\hline Sufficiently active & 56 & 82.4 & 12 & 17.6 & \\
\hline Unsufficiently active & 25 & 80.6 & 6 & 19.4 & \\
\hline \multicolumn{5}{|l|}{ Nutritional Status (BMI) } & 0.003 \\
\hline Undernutrition & 4 & 50.0 & 4 & 50.0 & \\
\hline Eutrophy & 32 & 74.4 & 11 & 25.6 & \\
\hline Overweight & 44 & 93.6 & 3 & 6.4 & \\
\hline \multicolumn{5}{|l|}{ Wasting syndrome } & 0.207 \\
\hline Yes & 9 & 69.2 & 4 & 30.8 & \\
\hline No & 72 & 83.7 & 14 & 16.3 & \\
\hline \multirow[t]{2}{*}{ Variable } & NoSarcop & & Sarcope & & $\mathrm{p}^{* *}$ \\
\hline & $M$ & SD & $M$ & SD & \\
\hline CD4+T(cells/mm $\left.\mathrm{mm}^{3}\right)$ & 652 & 348 & 497 & 322 & 0.121 \\
\hline \multirow[t]{2}{*}{ Variable } & No Sarco & & Sarcope & & $\mathrm{p}^{* * *}$ \\
\hline & Med & $\mathrm{IQ}$ & Med & $\mathrm{IQ}$ & \\
\hline Time since diagnosis & 10 & $6-12$ & 10 & $5-12$ & 0.806 \\
\hline Duration of ART & 60 & $24-138$ & 54 & $18-135$ & 0.870 \\
\hline
\end{tabular}

*Pearson's Chi-Square or Fisher's Exact. **Student's t test; ***Mann -Whitney U test.

BMI: Body Mass Index; CKD: Chronic Kidney Disease; DM: Diabetes Mellitus; IQ: Interquartile Interval; M: Mean; Med: Median; SAH: Systemic Arterial Hypertension; SD: Standard Deviation. 
Table 4. Factors associated with wasting syndrome in HIV-infected patients using antiretroviral therapy, $2017(n=99)$.

\begin{tabular}{|c|c|c|c|c|c|}
\hline \multirow[t]{2}{*}{ Variable } & \multicolumn{2}{|c|}{ Without Wasting Syndrome } & \multicolumn{2}{|c|}{ With Wasting Syndrome } & \multirow[t]{2}{*}{$\mathbf{p}^{*}$} \\
\hline & & & & & \\
\hline Sex & & & & & 0.075 \\
\hline Male & 61 & 91.0 & 6 & 9.0 & \\
\hline Female & 25 & 78.5 & 7 & 21.9 & \\
\hline Age Category & & & & & 0.513 \\
\hline Adult & 82 & 87.2 & 12 & 12.8 & \\
\hline Elderly & 4 & 80.0 & 1 & 20.0 & \\
\hline Education & & & & & 0.005 \\
\hline$\leq 9$ years & 28 & 73.7 & 10 & 26.3 & \\
\hline$>9$ years & 53 & 94.6 & 3 & 5.4 & \\
\hline Family income per capita & & & & & 0.041 \\
\hline 1st tertile $(>333.33)$ & 20 & 74.1 & 7 & 26.9 & \\
\hline 2nd tertile (333.33-1000.00) & 46 & 88.5 & 6 & 11.5 & \\
\hline 3rd tertile $(>1000.00)$ & 17 & 100.0 & 0 & 0 & \\
\hline Clinical variables Viral load & & & & & 0.578 \\
\hline Undetectable & 39 & 86.7 & 6 & 13.3 & \\
\hline Detectable & 29 & 87.9 & 4 & 12.1 & \\
\hline CD4+T (cells $\left./ \mathrm{mm}^{3}\right)$ & & & & & 0.069 \\
\hline$\leq 350$ & 14 & 73.7 & 5 & 26.3 & \\
\hline$>350$ & 55 & 90.2 & 6 & 9.8 & \\
\hline $\mathrm{SAH}$ & & & & & 0.491 \\
\hline Yes & 10 & 83.3 & 2 & 16.7 & \\
\hline No & 76 & 87.4 & 11 & 12.6 & \\
\hline DM & & & & & 0.176 \\
\hline Yes & 4 & 66.7 & 2 & 33.3 & \\
\hline No & 82 & 88.2 & 11 & 11.8 & \\
\hline CKD & & & & & 0.641 \\
\hline Yes & 12 & 80.0 & 1 & 20.0 & \\
\hline No & 82 & 87.2 & 4 & 12.8 & \\
\hline Anemia & & & & & 0.387 \\
\hline Yes & 12 & 80.0 & 3 & 20.0 & \\
\hline No & 63 & 86.3 & 10 & 13.7 & \\
\hline Fatigue & & & & & 0.359 \\
\hline Yes & 51 & 85.0 & 9 & 15.0 & \\
\hline No & 35 & 89.7 & 4 & 10.3 & \\
\hline Anorexia & & & & & 0.526 \\
\hline Yes & 17 & 89.5 & 2 & 10.5 & \\
\hline No & 69 & 86.3 & 11 & 13.8 & \\
\hline
\end{tabular}




\begin{tabular}{|c|c|c|c|c|c|c|}
\hline \multicolumn{2}{|l|}{ Variable } & \multicolumn{2}{|c|}{ Without Wasting Syndrome } & \multicolumn{2}{|c|}{ With Wasting Syndrome } & $\mathbf{p}^{*}$ \\
\hline \multicolumn{6}{|c|}{ Consumption of Alcoholic Beverages } & 0.362 \\
\hline Yes & & 41 & 89.1 & 5 & 10.9 & \\
\hline No & & 44 & 84.6 & 8 & 15.4 & \\
\hline \multicolumn{6}{|l|}{ Smoking } & 0.864 \\
\hline Smoker & & 16 & 84.2 & 3 & 15.8 & \\
\hline Non-smoking & & 53 & 88.3 & 7 & 11.7 & \\
\hline Former smoker & & 17 & 85.0 & 3 & 15.0 & \\
\hline \multicolumn{6}{|l|}{ Level of Physical Activity } & 0.060 \\
\hline Sufficiently active & & 62 & 91.2 & 6 & 8.8 & \\
\hline Unsufficiently active & & 24 & 77.4 & 7 & 22.6 & \\
\hline \multicolumn{6}{|l|}{ Nutritional Status (BMI) } & 0.138 \\
\hline Undernutrition & & 6 & 75.0 & 2 & 25.0 & \\
\hline Eutrophy & & 35 & 81.4 & 8 & 18.3 & \\
\hline Overweight & & 44 & 93.6 & 3 & 6.4 & \\
\hline \multirow{2}{*}{$\begin{array}{c}\text { Variable } \\
\text { M }\end{array}$} & \multicolumn{5}{|c|}{ Without Wasting SyndromeWith Wasting Syndrome } & $\mathrm{p}^{* *}$ \\
\hline & & SD & M & SD & & \\
\hline $\mathrm{CD} 4+\mathrm{T}\left(\right.$ cells $\left./ \mathrm{mm}^{3}\right)$ & & 654 & 321 & 429 & 449 & 0.045 \\
\hline \multirow[t]{2}{*}{ Variable } & \multicolumn{5}{|c|}{ Without Wasting SyndromeWith Wasting Syndrome } & $\mathrm{p}^{* * *}$ \\
\hline & & Med & IQ & Med & IQ & \\
\hline Time since diagnosis & & 60 & $24-144$ & 60 & $12-101$ & 0.278 \\
\hline Duration of ART & & 48 & $24-114$ & 24 & $12-96$ & 0.119 \\
\hline
\end{tabular}

* Pearson's Chi-Square or Fisher's Exact. ** Student's t test; *** Mann -Whitney U test.

BMI: Body Mass Index; CKD: Chronic Kidney Disease; DM: Diabetes Mellitus;

IQ: Interquartile Interval; M: Mean; Med: Median; SAH: Systemic Arterial Hypertension; SD: Standard Deviation.

\section{DISCUSSION}

Sarcopenia is associated with decreased quality of life and increased morbidity and mortality ${ }^{27,28}$. Therefore, the study of sarcopenia is clinically vital for the management and treatment of HIV positive patients. Although sarcopenia was initially described as a physiological aspect associated with aging, it is possible to find that sarcopenia is, in fact, associated with several diseases ${ }^{29,30,31}$. Research has shown that HIV-infected individuals are typically affected by a series of complications that are traditionally unrelated to AIDS. However, these complications are often known to be related to early aging, e.g. sarcopenia ${ }^{6,32}$.

The prevalence of sarcopenia found in the present research protocol was lower than that previously described by Neto et $\mathrm{a}^{11}$. Briefly, the work of Neto and colleagues compared the prevalence of sarcopenia in HIV-infected patients and patients not infected with HIV (serving as the control group.) Sarcopenia was observed in $24.2 \%$ of those infected. The difference in prevalence found between our present protocol and this previously mentioned study can be explained by the differences in average age among participants. The subjects in the present study had an average age of 40 years old, while the average age of participants in the Neto et al study was 59 years of age. Since sarcopenia is a syndrome that progresses with age, this circumstance may explain why there was a greater prevalence of the syndrome according to Neto et a ${ }^{11}$. 
Few studies have shown results regarding the combination of the three components that encompass sarcopenia. In a cohort study with middle-aged, HIV-infected adults using ART, $50 \%$ of physically-disabled adults met the criterion of low muscle mass that characterized sarcopenia ${ }^{33}$. However, the method utilized for the detection of muscle mass differs from that used in the current study, which is considered more sensitive. The findings reinforce the idea that the presence of sarcopenia can be related to a reduction of the functionality in those infected by HIV, therefore compromising the quality of life and increasing the risk of complications ${ }^{33,34}$. Taking all of these factors into consideration, it is noteworthy to mention the relevance of a systematic evaluation of this condition in the follow-up routine of HIV patients.

Regarding the severity of sarcopenia, we observed that $33 \%$ of our sarcopenic patients had severe sarcopenia, an unfavorable condition for the three diagnostic criteria: mass, strength and functionality. Our findings differ from those reported by Neto et al ${ }^{11}$ who evaluated patients with a mean age of 59 years and a BMI of $25.6 \mathrm{~kg} / \mathrm{m}^{2}$. Among non-sarcopenic patients, $16 \%$ of the patients studied presented pre-sarcopenia; a condition that already exposes the individual to a greater risk of developing osteoporosis, as reported in an investigation carried out in men with $\mathrm{HIV}^{35}$. In this published report, pre-sarcopenic patients had a higher risk of developing osteoporosis despite a recovery of CD4+T cells ${ }^{35}$. The presence of osteoporosis may increase the risk of falls and fractures that can be observed in the HIV-infected population ${ }^{6,36}$. In addition to the increased risk of developing comorbidities, the presence of sarcopenia may also be responsible for increased duration and number of hospitalizations, as well as healthcare costs ${ }^{37,38}$.

If we analyze the components that comprise the diagnosis of sarcopenia in our participants, despite the similar percentages among them (e.g. about $30 \%$ of the subjects), we observed that reduced muscle strength was present in a greater proportion of the test subjects compared to mass and functionality muscle. Manini and Clark point out that the loss of muscle strength could be more devastating than the changes in muscle mass itself ${ }^{39}$. It could be more devastating since loss of muscle strength can cause more adverse effects. This observation highlights the importance of the evaluation of muscle strength, even in those individuals with good muscle mass. This is especially relevant since studies have shown that muscle strength impairment is an independent risk factor for mortality in patients with $\mathrm{HIV}^{40,41}$.

Long before the beginning of studies relating sarcopenia to HIV, the malignant effects of weight loss, which also includes the loss of muscle mass, had already been studied in the HIV population, especially those without $A R T^{42}$. Even after the introduction of ART, HIV-associated wasting syndrome has remained a topic of study ${ }^{13}$. Wasting syndrome in the current study affected individuals to a lesser extent when compared to how sarcopenia affected them. Therefore, great attention should be given to how this condition threatens patient health. Effects can result in worse clinical outcomes and even higher mortality in cases of clients suffering from progressive weight loss ${ }^{12,15,43}$. High percentages of weight loss were found in a cohort conducted by Wanke et $\mathrm{al}^{14}$. This research showed that in $18 \%$ of HIV-infected patients, there was an unintentional weight loss higher than $10 \%$ between two follow-up visits. In addition, the prevalence of involuntary weight loss was higher that $5 \%$ in $21 \%$ of patients on regular ART. On the other hand, a study with more than 12,000 HIV patients by Siddiqui et al demonstrated a prevalence of $8.3 \%$ of HIV-associated wasting syndrome in patients who were using antiretroviral therapy. In addition, weight loss in these patients was associated with the presence of several comorbidities, as well as higher costs of hospital care ${ }^{44}$.

The consequences of wasting syndrome go beyond the immediate effects on health. Long-term effects have also been described in recent findings in the literature. It has recently been shown that the syndrome had a negative impact on muscle strength and physical function, with findings observed even years after stabilization of body weight ${ }^{16}$.

When our team evaluated the factors associated with the investigated conditions, we observed that sarcopenia was more prevalent in elderly compared to younger adults. In fact, aging, as well as HIV infection, is characterized by increased protein catabolism and subsequent muscle loss ${ }^{45}$.

Furthermore, the prevalence of sarcopenia was higher in malnourished patients, but it is important to emphasize that this condition was present in about $25 \%$ of eutrophic patients and in more than $6 \%$ of individuals who were overweight. These findings reinforce the importance of assessing sarcopenia independent of nutritional status, since its deleterious effects are not restricted to undernourished individuals. More recently, Erlandson et al showed increased mortality risk in those HIV infected subjects who presented reduction of limb muscle mass in the presence of sarcopenic obesity $^{33}$. Interestingly, many studies are finding an association between muscle mass reduction, increased adiposity and mortality in non-HIV-infected patients ${ }^{46,47,48}$.

Sarcopenia was also associated with DM. Park et al found that older individuals with type 2 diabetes had a $30 \%$ greater 3-year decline in muscle strength, when compared to their healthier counterparts, who did not present $\mathrm{DM}^{49}$. More recently, other research groups have demonstrated an association between DM and muscle impairment ${ }^{50,51,52}$. DM can contribute to sarcopenia, as it speeds up protein catabolism through the modifications generated by insulin resistance and glucose toxicity ${ }^{53,54}$. These results reinforce the need for better nutritional monitoring, particularly in those patients with HIV, who also present chronic diseases like DM. In addition to nutritional care, it is important to note that properly monitored exercise programs are able to preserve muscle mass, improve body composition, as well as increase the number of CD4+T cells, which contributes to improving the quality of life in the population living with HIV/AIDS ${ }^{55,56}$.

Although they were not associated in the present study, 
the coexistence of sarcopenia and wasting syndrome was found in a relatively small percentage of the sample (4\%). Special consideration should be given to these patients, as they simultaneously present two conditions associated with malignant outcomes and that may compromise clinical prognosis.

Wasting syndrome was associated with lower socioeconomic status, an association previously demonstrated by $\mathrm{Li}$ et $\mathrm{al}^{57}$. This research report indicated that lower socioeconomic status, among other factors, was a predictor of severe weight loss in HIV-infected patients. This observation was described after initiation of HAART ${ }^{57}$. Similar findings have also been reported in a study of women infected with HIV $^{58}$. It is reasonable to suggest that the association between wasting syndrome and lower socioeconomic status can be explained by the fact that people with better socioeconomic status may have better access to nutritionally adequate diets, as well as greater levels of education. These aspects can significantly contribute to the improvement of health care ${ }^{57}$.

Our findings also indicated that those with wasting syndrome had lower CD4+T cell counts. In agreement with these findings, it was demonstrated that weight and BMI were significantly lower when there were lower levels of CD4+ T cells ${ }^{59}$. In addition, the greatest weight loss occurred when CD4+T cells counts were lower than 600 cells $/ \mathrm{mm}^{3(60)}$. Data also show that the increase in CD4+T cell count associated with undetectable viral load would be able to minimize weight loss in HIV patients ${ }^{61}$.

Despite the interesting findings reported in the present study, it is important to point out some limitations that consequently limit the extent of the current research conclusions. First, the sample was taken from a single service and is relatively small. This last factor may have contributed to the differences not found, especially regarding the level of physical activity. However, while this limitation does not diminish the importance of this study, we acknowledge that any extrapolation of our results to other groups of HIV-infected patients should be done with great caution. Second, the use of anthropometry as a tool to assess muscle mass can also represent a limitation, since the best method for estimating muscle mass would be computed by tomography and magnetic resonance imaging. However, because of the higher cost of these methods and the limited access to equipment, DXA (Dual energy X-ray absorptiometry) is suggested as an alternative method, both for research and in clinical practice ${ }^{62}$.

Additionally, anthropometric assessment is used in lieu of more sophisticated methods that are often unavailable in clinical practice. Therefore, due to these potential limitations, it is possible that the number of individuals with reduced muscle mass may be underestimated. Lastly, it is important to mention that the lack of biochemical evaluation prevented us from incrementing our conclusions, primarily in regard to inflammatory markers, known to be associated with sarcopenia and greater weight loss.

\section{CONCLUSION}

The current findings allow us to conclude that the prevalence of sarcopenia in this study appeared to be lower than that found in the few studies available in published literature, mainly due to differences in sample characteristics and methodologies used to diagnose sarcopenia. We observed that sarcopenia was more prevalent in elderly, diabetic and malnourished patients, but was also present in individuals with normal or overweight nutritional status. Wasting syndrome was less prevalent than sarcopenia, and the syndrome was associated with lower socioeconomic status and lower CD4 + T cells count.

Sarcopenia and wasting syndrome are both significant clinical problems that can increase morbidity and mortality risks in patients infected with HIV. Therefore, adequate nutritional monitoring is recommended, as well as routine evaluation of these two conditions. Inexpensive and practical clinical assessments can potentially avoid, or at least, delay the onset of these undesirable conditions. As a result, patients affected by the devastating HIV virus will be able to experience a better quality of life as well as an improved clinical prognosis.

\section{REFERENCES}

1. Passaes C, Sáez-Cirión, A. HIV cure research: Advances and rospects. Virology. 2014; 454: 340-352.

2. Deeks S, Lewin S, Havlir D. The end of AIDS: HIV infection as a chronic disease. Lancet. 2013; 382: 1525-1533.

3. Keithley IK, Swanson B. "HIV-associated wasting." I Assoc Nurses AIDS Care. 2013; 24: 103-S111.

4. Babameto G, Kotler D. Malnutrition in HIV Infection. Gastroenterol Clin North Am. 1997; 26: 393-415.

5. Shevitz A, Knox T. Nutrition in the era of highly active antiretroviral therapy. Clin Infect Dis. 2001; 32: 1769-1775.

6. Hawkins K, Brown T, Margolick J, Erlandson K. Geriatric syndromes. AIDS. 2017; 31: 137-146.

7. Goodpaster BH, Park SW, Harris TB, Kritchevsky SB, Nevitt $M$, Schwartz AV, et al. The loss of skeletal muscle strength, mass, and quality in older adults: the health, aging and body composition study. J Gerontol Ser A, Biol Sci Med Sci. 2006; 61: 1059-1064.

8. Delmonico MI, Harris TB, Lee JS, Visser M, Nevitt M, Kritchevsky $S B$, et al. Alternative definitions of sarcopenia, lower extremity performance, and functional impairment with aging in older men and women. J Am Geriatr Soc. 2007; 55: 769-774.

9. Cruz-Jentoft AJ, Baeyens JP, Bauer JM, Boirie Y, Cederholm T, Landi F, et al. Sarcopenia: European consensus on definition and diagnosis: Report of the European Working Group on Sarcopenia in Older People. Age Ageing 2010; 39: 412-423.

10. Wasserman P, Segal-Maurer S, Rubin, D. High prevalence of low skeletal muscle mass associated with male gender in midlife and older HIV-infected persons despite CD4 cell reconstitution and viral suppression. J Int Assoc Provid AIDS Care. 2014; 13: 145-152.

11. Neto $P$, da Silva LF, Sales MC, Scaramussa ES, da Paz CJC, Morelato RL. Human immunodeficiency virus infection and its association with sarcopenia. Braz J of Infect Dis. 2016; 20: 99-102.

12. Tang A, Forrester J, Spiegelman D, Knox T, Tchetgen E, Gorbach S. Weight Loss and Survival in HIV-Positive Patients 
in the Era of Highly Active Antiretroviral Therapy. J Acquir Immune Defic Syndr. 2002; 31: 230-236.

13. Mangili A, Murman D, Zampini A, Wanke C, Mayer K. Nutrition and HIV Infection: Review of weight loss and wasting in the era of highly active antiretroviral therapy from the Nutrition for Healthy Living Cohort. Clin Infect Dis. 2006; 42: 836-842.

14. Wanke C, Silva M, Knox T, Forrester I, Speigelman D, Gorbach $S$. Weight loss and wasting remain common complications in individuals infected with human immunodeficiency virus in the era of highly active antiretroviral therapy. Clin Infect Dis. 2000; 31: 803-805.

15. Wheeler DA, Gibert CL, Launer CA, Muurahainen N, Elion RA, Abrams DI, et al. Weight Loss as a predictor of survival and disease progression in HIV infection. J Acquir Immune Defic Syndr. 1998; 18: 80-85.

16. Erlandson KM, Xiuhong LI, Abraham AG, Margolick JB, Lake JE, Palella Jr FJ, et al. Long-term impact of HIV wasting on physical function in the Multicenter AIDS Cohort Study. AIDS. 2016; 30: 445-454.

17. Morley JE, Vellas B, Van Kan G A, Anker SD, Bauer JM, Bernabei $R$, et al. Frailty consensus: a call to action. I Am Med Dir Assoc. 2013; 14: 392-397.

18. Frisancho AR. Anthropometric Standards of the assessment of growth and nutritional status. The University of Michigan Press, Michigan, 1990.

19. Van Kan GA, Rolland Y, Andrieu S, Bauer J, Beauchet O, Bonnefoy $M$, et al. Gait speed at usual pace as a predictor of adverse outcomes in community-dwelling older people an International Academy on Nutrition and Aging (IANA) Task Force. J Nutr Health Aging. 2009; 13: 881-889.

20. Wanke C, Kotler D, and HIV Wasting Collaborative Consensus Committee. Collaborative recommendations: the approach to diagnosis and treatment of HIV wasting. J Acquir Immune Defic Syndr. 2004; 37: 284-288.

21. Sands, JK. Nursing Diagnoses: Definitions and Classification 2001-2002. Family \& Community Health, 2002. 24: 57-58.

22. Fini A, Cruz D. Psychometric properties of Dutch Fatigue Scale and Dutch Exertion Fatigue Scale: Brazilian version. Rev Bras Enferm. 2010; 63: 216-221.

23. Sties SW, Gonzáles Al, da Silveira Viana M, Brandt $R$, Bertin RL, Goldfeder R, et al. Appetite Simplified Nutrition Questionnaire (QNSA) for use in cardiopulmonary and metabolic rehabilitation programs. Rev Bras Med Esporte. 2012;18: 313-317.

24. International Physical Activity Questionnaire (IPAQ). (2001). Acessed 30 october 2016. <http://www.ipaq.ki.se>.

25. World Health Organization. Obesity: preventing and managing the global epidemic. Report of a WHO Consultation presented at the World Health Organization. Geneva, Switzerland: WHO; June 3-5; 1997.

26. Lipschitz D. Screening for nutritional status in the elderly. Prim Care. 1994; 21: 55-67.

27. Von Haehling S, Morley J, Anker S. An overview of sarcopenia: facts and numbers on prevalence and clinical impact. J Cachexia Sarcopenia Muscle. 2010; 1: 129-133.

28. Kim T, Choi K. Sarcopenia: Definition, epidemiology, and pathophysiology. J bone Metab. 2013; 20: 1-10.

29. Prado C, Lieffers J, Bowthorpe L, Baracos V, Mourtzakis M, McCargar L. Sarcopenia and Physical Function: In Overweight Patients with Advanced Cancer. Can I Diet Pract Res. 2013; 74: 69-74.

30. Jones SE, Maddocks M, Kon SS, Canavan IL, Nolan CM, Clark $A L$, et al. Sarcopenia in COPD: prevalence, clinical correlates and response to pulmonary rehabilitation. Thorax. 2015; 70: 213-218.

31. Pereira RA, Cordeiro AC, Avesani CM, Carrero Jl, Lindholm $B$, Amparo FC, et al. Sarcopenia in chronic kidney disease on conservative therapy: prevalence and association with mortality. Nephrol Dial Transplant. 2015; 30: 1718-1725.

32. Wilson I, Jacobson $D$, Roubenoff $R$, Spiegelman $D, \operatorname{Knox} T$, Gorbach $S$. Changes in lean body mass and total body weight are weakly associated with physical functioning in patients with HIV infection. HIV Med. 2002; 3: 263-270.

33. Erlandson K, Allshouse A, Jankowski C, MaWhinney S, Kohrt W, Campbell, T. Functional Impairment Is Associated With Low Bone and Muscle Mass Among Persons Aging With HIV Infection. J Acquir Immune Defic Syndr. 2013; 63: 209-215.

34. Richert L, Dehail P, Mercié P, Dauchy FA, Bruyand M, Greib $C$, et al. High frequency of poor locomotor performance in HIV-infected patients. AIDS. 2011; 25: 797-805.

35. Dutta D, Sharma M, Bansal R, Sharma N, Garga UC, Anand $A$, et al. Low skeletal mass is an important predictor of osteoporosis in HIV infected men in India. Endokrynol Pol. 2017; 68: 642-651.

36. Dong H, Cortés Y, Shiau S, Yin M. Osteoporosis and fractures in HIV/hepatitis C virus coinfection. AIDS. 2014; 28: 21192131.

37. Berger M, Doherty T. Sarcopenia: prevalence, mechanisms, and functional consequences. In: Body Composition and Aging. Karger Publishers, New York, 2010; 37: 94-114.

38. Young B, Dao C, Buchacz K, Baker R, Brooks, J. Increased rates of bone fracture among HIV-infected persons in the HIV Outpatient Study (HOPS) compared with the US general population, 2000-2006. Clin Infect Dis. 2011; 52: 1061-1068.

39. Manini T, Clark B. Dynapenia and aging: An update. J Gerontol Ser A, Biol Sci Med Sci. 2011; 67: 28-40.

40. Leong DP, Teo KK, Rangarajan S, Lopez-Jaramillo P, Avezum Ir A, Orlandini $A$, et al. Prognostic value of grip strength: findings from the Prospective Urban Rural Epidemiology (PURE) study. Lancet. 2015; 386: 266-273.

41. Filteau S, PrayGod G, Woodd SL, Friis H, Heimburger $D C$, Koethe $J R$, et al. Nutritional status is the major factor affecting grip strength of African HIV patients before and during antiretroviral treatment. Trop Med Int Health. 2017; 22: 1302-1313.

42. Kotler D, Tierney A, Wang J, Pierson R. Magnitude of bodycell-mass depletion and the timing of death from wasting in AIDS. Am J Clin Nutr. 1989; 50: 444-447.

43. Palenicek JP, Graham NM, He YD, Hoover DA, Oishi JS, Kingsley L, et al. Weight Loss Prior to Clinical AIDS as a Predictor of Survival. J Acquir Immune Defic Syndr Hum Retrovirol. 1995; 10: 366-373.

44. Siddiqui J, Phillips A, Freedland E, Sklar A, Darkow T, Harley C. Prevalence and cost of HIV-associated weight loss in a managed care population. Curr Med Res Opin. 2009; 25: 1307-1317.

45. Szulc P, Munoz F, Marchand F, Chapurlat R, Delmas P. Rapid loss of appendicular skeletal muscle mass is associated with higher all-cause mortality in older men: the prospective MINOS study. Am J Clin Nutr. 2010; 91: 1227-1236.

46. Wannamethee S, Shaper A, Lennon L, Whincup P. Decreased muscle mass and increased central adiposity are independently related to mortality in older men. Am J Clin Nutr. 2007; 86: 1339-1346.

47. Mason C, Craig C, Katzmarzyk P. Influence of Central and Extremity Circumferences on All-cause Mortality in Men and 
Women. Obesity. 2008; 16: 2690-2695.

48. Landi F, Russo A, Liperoti R, Pahor M, Tosato M, Capoluongo $E$, et al. Midarm muscle circumference, physical performance and mortality: Results from the aging and longevity study in the Sirente geographic area (ilSIRENTE study). Clin Nutr. 2010; 29: 441-447.

49. Park SW, Goodpaster BH, Strotmeyer ES, Kuller LH, Broudeau $R$, Kammerer $C$, et al. Accelerated loss of skeletal muscle strength in older adults with type 2 diabetes: The Health, Aging, and Body Composition Study. Diabetes Care. 2007; 30: 1507-1512.

50. Leenders $M$, Verdijk $L B$, van der Hoeven L, Adam Jl, Van Kranenburg J, Nilwik $R$, et al. Patients with type 2 diabetes show a greater decline in muscle mass, muscle strength, and functional capacity with aging. I Am Med Dir Assoc. 2013; 14: 585-592.

51. Kim K, Park K, Kim M, Kim S, Cho Y, Park S. Type 2 diabetes is associated with low muscle mass in older adults. Geriatr Gerontol Int. 2014; 14: 115-121.

52. Guerrero N, Bunout D, Hirsch $S$, et al. Premature loss of muscle mass and function in type 2 diabetes. Diabetes Res Clin Pract. 2016; 117: 32-38.

53. Landi F, Onder G, Bernabei R. Sarcopenia and diabetes: two sides of the same coin. J Am Med Dir Assoc. 2013; 14: 540-541.

54. Morley J, Malmstrom T, Rodriguez-Mañas L, Sinclair A. Frailty, sarcopenia and diabetes. I Am Med Dir Assoc. 2014; 15: 853-859.

55. Paes LS, Borges JP, Dos Santos FM, de Oliveira TP, Dupin JG, Harris EA, et al. Effects of a 2-year supervised exercise program upon the body composition and muscular performance of HIV-infected patients. Open AIDS J. 2015; 9: 80-88.

56. de Brito-Neto JG, de Andrade MF, de Almeida VD, Paiva DCC, de Morais NM, Bezerra CM, et al. Strength training improves body composition, muscle strength and increases CD4+ T lymphocyte levels in people living with HIVIAIDS. Infect Dis Rep. 2019; 11: 7925.

57. Li N, Spiegelman D, Drain P, Mwiru RS, Mugusi F, Chalamilla $G$, et al. Predictors of weight loss after HAART initiation among HIV-infected adults in Tanzania. AIDS. 2012; 26: 577-585.

58. Villamor E, Saathoff E, Manji K, Msamanga G, Hunter D, Fawzi W. Vitamin supplements, socioeconomic status, and morbidity events as predictors of wasting in HIV-infected women from Tanzania. Am J Clin Nutr. 2005; 82: 857-865.

59. National Center for Health Statistics. Third national health and nutrition examination survey, 1988-1994. NHANES III laboratory data file. Hyattsville, MD: Centers for Disease Control and Prevention, Atlanta,USA, 1996.

60. Forrester J, Spiegelman D, Woods M, Knox T, Fauntleroy J, Gorbach S. Weight and body composition in a cohort of HIV-positive men and women. Public Health Nutr. 2001; 4: 743-747.

61. Mwamburi DM, Wilson IB, Jacobson DL, Spiegelman D, Gorbach SL, Knox TA, et al. Understanding the Role of HIV Load in Determining Weight Change in the Era of Highly Active Antiretroviral Therapy. Clin Infect Dis. 2005; 40: 167-173.

62. Chien M, Huang T, Wu Y. Prevalence of Sarcopenia Estimated Using a Bioelectrical Impedance Analysis Prediction Equation in Community-Dwelling Elderly People in Taiwan. J Am Geriatr Soc. 2008; 56: 1710-1715. 